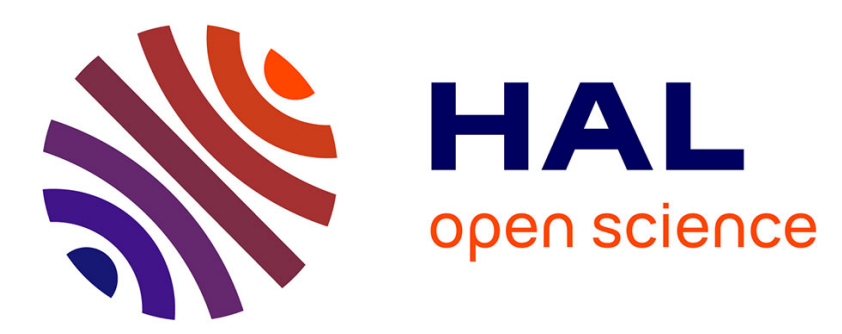

\title{
Attitude and Handling Improvements Through Gain-scheduled Suspensions and Brakes Control
}

Charles Poussot-Vassal, Olivier Sename, Luc Dugard, Peter Gaspar, Zoltan Szabo, Jozsef Bokor

\section{- To cite this version:}

Charles Poussot-Vassal, Olivier Sename, Luc Dugard, Peter Gaspar, Zoltan Szabo, et al.. Attitude and Handling Improvements Through Gain-scheduled Suspensions and Brakes Control. Control Engineering Practice, 2011, 19 (3 - Special Issue of the 17th IFAC World Congress), pp.252-263. 10.1016/j.conengprac.2010.05.016 . hal-00387610

\section{HAL Id: hal-00387610 https://hal.science/hal-00387610}

Submitted on 10 Nov 2010

HAL is a multi-disciplinary open access archive for the deposit and dissemination of scientific research documents, whether they are published or not. The documents may come from teaching and research institutions in France or abroad, or from public or private research centers.
L'archive ouverte pluridisciplinaire HAL, est destinée au dépôt et à la diffusion de documents scientifiques de niveau recherche, publiés ou non, émanant des établissements d'enseignement et de recherche français ou étrangers, des laboratoires publics ou privés. 


\title{
Attitude and Handling Improvements Through Gain-scheduled Suspensions and Brakes Control
}

\author{
C. Poussot-Vassal ${ }^{1 \text { a }}$ O. Sename ${ }^{b}$ L. Dugard ${ }^{b}$ P. Gáspár ${ }^{c}$ Z. Szabóc ${ }^{c}$ \\ J. Bokor ${ }^{\mathrm{c}}$ \\ a Systems Control and Flight Dynamics Department (DCSD) of ONERA, 2 Avenue Edouard Belin, \\ BP 74025, 31055 Toulouse Cedex, FRANCE. Corresponding author. \\ ${ }^{\mathrm{b}}$ GIPSA-lab, Control Systems Department, Grenoble University - Domaine Universitaire, BP46, \\ 38402 Saint Martin d'Hères - Cedex FRANCE \\ ${ }^{\mathrm{c}}$ Computer and Automation Research Institute, Hungarian Academy of Sciences, Kende u. 13-17, \\ H-1111, Budapest, HUNGARY
}

\begin{abstract}
In this paper, the problem of comfort and handling improvements of a ground vehicle is treated through the joint control of the suspension and braking systems. Two $\mathcal{H}_{\infty}$ gain-scheduled controllers are synthesized to achieve, attitude and yaw performances according to the driving situation, observed through of a simple vehicle monitor. The proposed strategy tackles the nonlinear tire braking force in an original way and meets the situation dependent objectives of the vehicle in a unified framework. Simulations on a complex nonlinear full vehicle model, validated using experimental data obtained on a real vehicle, illustrate the improvements brought by the proposed approach.
\end{abstract}

Key words: $\mathcal{H}_{\infty}$, Linear Parameter Varying, Suspensions, Brakes, Global Chassis Control, Anti-locking Braking System, Electronic Stability Control.

\section{Introduction}

\subsection{Motivations}

In most automotive control design approaches, suspension and braking control systems are separately synthesized and locally tuned without considering their interaction

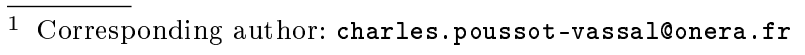


explicitly. This kind of approach may lead to conflicting or sub-optimal control choices. As an illustration, suspensions are usually designed to improve either comfort (ABC, Active Body Control) or road-holding. Conversely, the braking system is used to tackle emergency situations such as slipping (ABS, Anti-locking Braking System) (see e.g. Denny 2005, Tanelli et al. 2007, Botero et al. 2007) or important lateral and yaw accelerations, when the driver is no longer able to stabilize the vehicle (ESC, Electronic Stability Control).

Nowadays, academic and industrial research communities are very active in the Global Chassis Control (GCC) field. This latter aims to improve both comfort and safety on commercial cars, by the development of integrated control strategies, effective over many different driving situations (Canale et al. 2007, Chou and d'Andréa Novel 2005, Gáspár et al. 2007, Poussot-Vassal et al. 2008a).

From a control point of view, the GCC synthesis leads to various problems such as MIMO (Multiple Input Multiple Output) controller design, robustness analysis, performance variations, etc. Even if the final GCC should include all the actuators and handle a hierarchy in their activation, the present paper focusses on active suspension and braking collaboration.

\subsection{Problem statement and contribution}

This work treats the vertical and the yaw motions control of a commercial light vehicle. Using the LPV (Linear Parameter Varying) control theory and grounded on Gáspár et al. (2007) results, a design methodology for an integrated global chassis controller is proposed.

More specifically, the proposed LPV $/ \mathcal{H}_{\infty}$ based strategy involves active suspensions and rear brakes to (i) guarantee comfort in normal cruise situations and (ii) to improve vehicle stability when emergency situations are detected (e.g. undesirable yaw rate, skidding, etc.). Figure 1 illustrates the proposed global control scheme interconnection with the vehicle system.

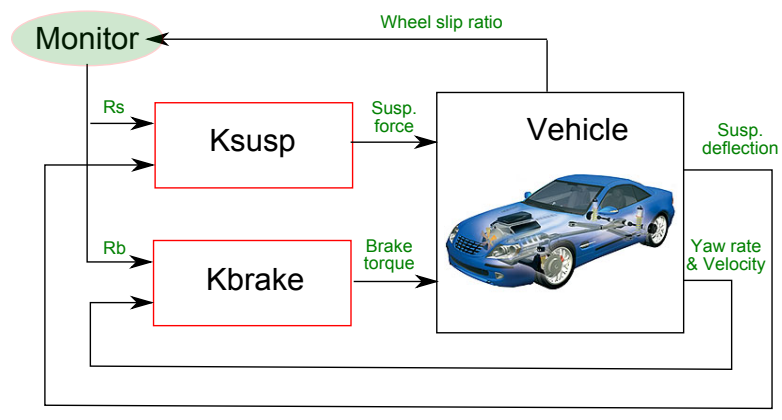

Fig. 1. General control structure.

The contribution of this works is in twofold: first, the control structure achieves adaptive performances thanks to two external controller parameters fed by the monitor, while guaranteeing robustness properties and internal stability. Secondly, through a dedicated 
parameter, the braking controller always reproduces the ABS principle in an original way. The proposed design performances are assessed on a complex full vehicle model.

\subsection{Paper structure and notations}

The paper is structured as follows: Section 2 introduces the used nonlinear vehicle model, which has been validated on a real experimental vehicle ${ }^{2}$. The main contribution i.e. the gain-scheduled suspension and braking controller design procedure is provided in Section 3. In Section 4, typical driving situations are simulated on the nonlinear model and are compared with a classic fixed gain approach (LTI design), illustrating the benefits of the proposed parametrized design. Conclusions are given in Section 5.

Mathematical notations are standard: $I_{n}$ denotes the identity matrix of order $n$, then $\left[\begin{array}{cc}A & (\star)^{T} \\ B & C\end{array}\right]$ is equivalent to $\left[\begin{array}{cc}A & B^{T} \\ B & C\end{array}\right]$.

\section{Full vehicle model}

This Section is devoted to the description of the nonlinear full vehicle model. This model is based on results obtained in the literature (Chou and d'Andréa Novel 2005, Gillespie 1992, Zin 2005). Additional analysis and discussions are also available in PoussotVassal (2008) Ph.D. thesis (Chapters 3 \& 4).

Throughout the paper, the following notations will be adopted: subscripts $i=\{f, r\}$ and $j=\{l, r\}$ are used to identify vehicle front, rear and left, right positions, respectively. The subscripts $s$ and $t$ indicate the forces provided by suspensions and tires, respectively. The subscripts $x, y$ and $z$ indicate forces or dynamical variables in the longitudinal, lateral and vertical axes, respectively. Let $v=\sqrt{v_{x}^{2}+v_{y}^{2}}$ denote the vehicle velocity, $R_{i j}=R-\left(z_{u s_{i j}}-z_{r_{i j}}\right)$ the effective tire radius, $z_{\text {def }_{i j}}$ denotes the suspension deflection at each corner of the vehicle and $m=m_{s}+m_{u s_{f l}}+m_{u s_{f r}}+m_{u s_{r l}}+m_{u s_{r r}}$ the total vehicle mass. $\delta$ is the steering angle, $u_{i j}$ the suspension additional force and $T_{b_{i j}}$, the torque provided by the braking actuator (see Section 3 ). Table 1 summarizes the model parameters, identified on a Renault Mégane Coupé, a sport-oriented car.

\subsection{Dynamical equations}

The chassis vertical $\left(z_{s}\right)$, longitudinal $(x)$, lateral $(y)$, roll $(\theta)$, pitch $(\phi)$ and yaw $(\psi)$ dynamics are given by the first 6 equations of (1), where $v_{x}$ and $v_{y}$ denote the $\mathrm{x}$ - and y-directional velocities of the chassis, and $\dot{z}_{s}$ is the z-directional velocity of the suspended mass. The vertical $\left(z_{u s_{i j}}\right)$ and rotational $\left(\omega_{i j}\right)$ motions of the wheels and center of gravity sideslip angle $\left(\beta_{c o g}\right)$ dynamics are given by the last 3 equations of $(1)$, where $\dot{z}_{u s_{i j}}$ is the z-directional velocity of the unsprung mass at the position indicated by $i, j$. As for forces,

\footnotetext{
${ }_{2}$ In a collaborative work with Pr. Michel Basset, G. Pouly and C. Lamy with the MIAM research team of the Université de Haute Alsace (see Poussot-Vassal 2008)
} 


\begin{tabular}{|c|c|c|c|}
\hline Symbol & Value & Unit & Signification \\
\hline$m_{s}$ & 350 & $k g$ & suspended mass \\
\hline$m_{u s_{f j}}$ & 35 & $k g$ & front unsprung mass \\
\hline$m_{u s_{r j}}$ & 32.5 & $k g$ & rear unsprung mass \\
\hline$I_{x} ; I_{y} ; I_{z}$ & $250 ; 1400 ; 679$ & $k g \cdot m^{2}$ & roll, pitch, yaw inertia \\
\hline$I_{y}$ & 1400 & $k g \cdot m^{2}$ & pitch inertia \\
\hline$I_{z}$ & 679 & $k g \cdot m^{2}$ & yaw inertia \\
\hline$I_{w}$ & 1 & $\mathrm{~kg} \cdot \mathrm{m}^{2}$ & wheel inertia \\
\hline$t_{f} ; t_{r}$ & $1.4 ; 1.4$ & $m$ & front, rear axle \\
\hline$l_{f} ; l_{r}$ & $1.4 ; 1$ & $m$ & COG-front, rear distance \\
\hline$R$ & 0.3 & $m$ & nominal wheel radius \\
\hline$h$ & 0.4 & $m$ & chassis height \\
\hline$k_{t_{i j}}$ & 208000 & $N / m$ & tire stiffness \\
\hline$c_{t_{i j}}$ & 10 & $N / m / s$ & tire damping \\
\hline$b_{t}$ & 8.3278 & - & lateral tire parameter \\
\hline$c_{t}$ & 1.1009 & - & lateral tire parameter \\
\hline$d_{t}$ & 2268 & - & lateral tire parameter \\
\hline$e_{t}$ & -1.1661 & - & lateral tire parameter \\
\hline$g$ & 9.81 & $m / s^{2}$ & gravitational constant \\
\hline
\end{tabular}

Table 1

Renault Mégane Coupé parameters.

$$
\left\{\begin{aligned}
\dot{v}_{x} & =-\left(F_{t x_{f}} \cos (\delta)+F_{t x_{r}}+F_{t y_{f}} \sin (\delta)\right) / m-\dot{\psi} v_{y} \\
\dot{v}_{y} & =\left(-F_{t x_{f}} \sin (\delta)+F_{t y_{r}}+F_{t y_{f}} \cos (\delta)\right) / m+\dot{\psi} v_{x} \\
\ddot{z}_{s} & =-\left(F_{s z_{f}}+F_{s z_{r}}+F_{d z}\right) / m_{s} \\
\ddot{\theta} & =\left(\left(F_{s z_{r l}}-F_{s z_{r r}}\right) t_{r}+\left(F_{s z_{f l}}-F_{s z_{f r}}\right) t_{f}+m h \dot{v}_{y}\right) / I_{x} \\
\ddot{\phi} & =\left(F_{s z_{f}} l_{f}-F_{s z_{r}} l_{r}-m h \dot{v}_{x}\right) / I_{y} \\
\ddot{\psi} & =\left(l_{f}\left(-F_{t x_{f}} \sin (\delta)+F_{t y_{f}} \cos (\delta)\right)-l_{r} F_{t y_{r}}+\left(F_{t x_{f r}}-F_{t x_{f l}}\right) t_{f} \cos (\delta)\right. \\
& \left.-\left(F_{t x_{r r}}-F_{t x_{r l}}\right) t_{r}+M_{d z}\right) / I_{z} \\
\ddot{z}_{u s_{i j}} & =\left(F_{s z_{i j}}-F_{t z_{i j}}\right) / m_{u s_{i j}} \\
\dot{\omega}_{i j} & =\left(R_{i j} F_{t x_{i j}}-T_{b_{i j}}\right) / I_{w} \\
\dot{\beta}_{c o g} & =\left(F_{t y_{f}}+F_{t y_{r}}\right) /\left(m v_{x}\right)+\dot{\psi}
\end{aligned}\right.
$$

$F_{t x_{f}}$ is the x-directional front tire force, $F_{s z_{i j}}$ is the z-directional suspension force at the position indicated by $i, j$, etc. Those forces are mutually related as: 


$$
\begin{aligned}
& F_{t x_{i}}=F_{t x_{i l}}+F_{t x_{i r}} \\
& F_{t y_{i}}=F_{t y_{i l}}+F_{t y_{i r}} \quad \text { where } i=\{f, r\} \\
& F_{t z_{i}}=F_{t z_{i l}}+F_{t z_{i r}} \\
& F_{s z_{i}}=F_{s z_{i l}}+F_{s z_{i r}}
\end{aligned}
$$

Finally, $d$ subscripts represent disturbance force or moment (e.g. $F_{d z}$ is the vertical force disturbance and $M_{d z}$ is the disturbance moment along the z-axis).

\subsection{Suspensions model $\left(F_{s z}\right)$}

Suspensions are usually modelled by a spring and a damping element. On real vehicles, their characteristics are nonlinear (see e.g. Zin et al. 2008). In this paper, the next suspension model is adopted:

$$
F_{s z_{i j}}=F_{k_{i j}}\left(z_{s_{i j}}-z_{u s_{i j}}\right)+F_{c_{i j}}\left(\dot{z}_{s_{i j}}-\dot{z}_{u s_{i j}}\right)+u_{i j}
$$

where $F_{k_{i j}}($.$) and F_{c_{i j}}($.$) are the nonlinear stiffness and damping force characteristics$ of the passive suspension system, function of the deflection $\left(z_{d e f_{i j}}=z_{s_{i j}}-z_{u s_{i j}}\right)$ and deflection velocity $\left(\dot{z}_{d e f_{i j}}=\dot{z}_{s_{i j}}-\dot{z}_{u s_{i j}}\right)$, respectively (illustrations of these forces are given in Poussot-Vassal et al. (2008c)). In the above, $u_{i j}$ is the additive force of the active suspension, so $u_{i j}=0$ for uncontrolled vehicles.

\subsection{Tires model}

Wheel and tire/road contact modeling is a difficult problem and still remains a wide research area (see e.g. Denny 2005, Kiencke and Nielsen 2000, Canudas-de-Wit et al. 2003, Velenis et al. 2005). Here, based on results given in Kiencke and Nielsen (2000), the following tire model is adopted (see also Figures 2 and 3 ).

\subsubsection{Longitudinal tire model $\left(F_{t x}\right)$}

The longitudinal Burkhardt model is given as:

$$
F_{t x_{i j}}=\left(\vartheta_{1}\left(1-e^{-\lambda_{i j} \vartheta_{2}}\right)-\lambda_{i j} \vartheta_{3}\right) F_{n_{i j}}
$$

where $\Theta_{\text {road type }}=\left[\vartheta_{1}, \vartheta_{2}, \vartheta_{3}\right]$ gives the longitudinal road friction shape according to the considered road condition. $F_{n_{i j}}=-F_{t z_{i j}}+g\left(m_{u s_{i j}}+m_{s} / 4\right)$ holds for the normal load applied on each wheel of the vehicle and $\lambda_{i j}$ is the longitudinal wheel slip ratio defined as:

$$
\lambda_{i j}=\frac{R_{i j} \omega_{i j}-v_{i j}}{\max \left\{\left|R_{i j} \omega_{i j}\right|,\left|v_{i j}\right|\right\}}
$$

where $v_{i j}$ is the vehicle velocity at each corner of the vehicle.

\subsubsection{Lateral tire model $\left(F_{t y}\right)$}

The lateral tire force is a modified version of the Pacejka magic formulae. It is given by formulae (6) and illustrated on Figure 3: 


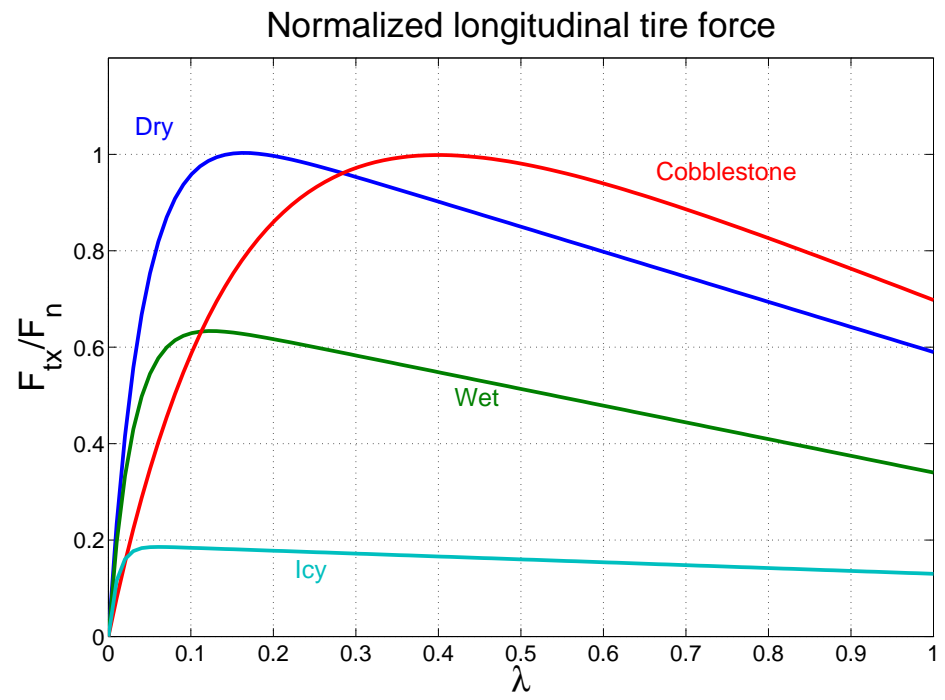

Fig. 2. Longitudinal normalized tire friction force $F_{t x_{i j}} / F_{n_{i j}}$ for different kinds of road adhesion, as a function of $\lambda$, the slip ratio. $\Theta_{d r y}=[1.11,23.99,0.52], \Theta_{\text {wet }}=[0.687,33.822,0.347]$, $\Theta_{\text {cobblestone }}=[1.37,6.46,0.67], \Theta_{\text {ice }}=[0.19,94.13,0.06]$.

$$
\begin{aligned}
F_{t y_{i j}} & =D e^{-6\left|\lambda_{i j}\right|^{5}} \sin \left(\Phi_{i j}\right) \\
\Phi_{i j} & =C \arctan \left(B(1-E) \beta_{i j}+E \arctan \left(B \beta_{i j}\right)\right)
\end{aligned}
$$

where $\beta_{f j}=\beta_{f}=-\beta_{c o g}-l_{f} \frac{\dot{\psi}}{v_{x}}+\delta$ and $\beta_{r j}=\beta_{r}=-\beta_{c o g}+l_{r} \frac{\dot{\psi}}{v_{x}}$ are the front and rear sideslip angles, respectively. $B=(2-\mu) b_{t}, C=(5 / 4-\mu / 4) c_{t}, D=d_{t} \mu$ and $E=e_{t}$ are the lateral tire parameters that are function of the tire/road adhesion coefficient $\mu \in[0,1]$. The factor $e^{-6\left|\lambda_{i j}\right|^{5}}$ in the first equation is inserted by the author to model the fact that lateral friction force decreases when slipping occurs. When vehicle is slipping, it is no longer manoeuvrable, therefore, $\lim _{\lambda_{i j} \rightarrow|1|} F_{t y_{i j}}=0$.

\subsubsection{Vertical tire model $\left(F_{t z}\right)$}

Finally, the vertical forces are linearly described by $F_{t z_{i j}}=k_{t_{i j}}\left(z_{u s_{i j}}-z_{r_{i j}}\right)+c_{t_{i j}}\left(\dot{z}_{u s_{i j}}-\right.$ $\left.\dot{z}_{r_{i j}}\right)$, where $k_{t_{i j}}$ and $c_{t_{i j}}$ are the tire vertical stiffness and damping constant respectively. $z_{u s_{i j}}$ and $z_{r_{i j}}$ are the unsprung mass displacement and road unevenness, respectively.

\subsection{Actuators dynamic}

In the presented approach, EMB (Electro-Mechanical Brake) and AS (Active Suspension) actuators are considered. The former allows to adjust the braking torque continuously. The latter is an electric actuator mounted on the suspension system allowing for force generation. These actuators will be modelled as first order low-pass transfer functions:

- The EMB actuators are modelled as:

$$
\dot{T}_{b_{r j}}=\varpi\left(T_{b_{r j}}^{0}-T_{b_{r j}}\right)
$$



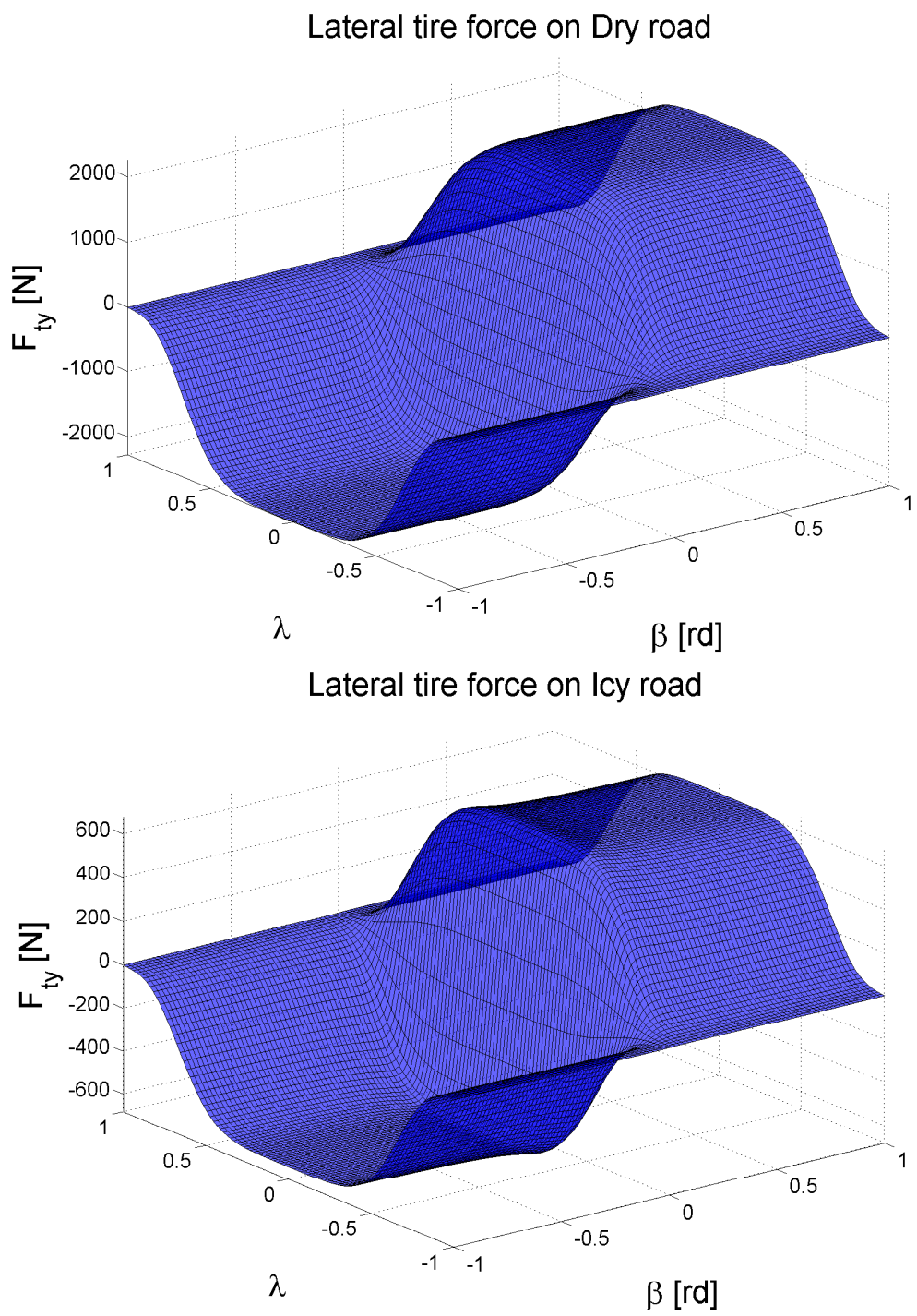

Fig. 3. Lateral tire friction force $F_{t y_{i j}}$ for a dry (top frame, $\mu=1$ ) and a wet (bottom frame, $\mu=0.2$ ) road as a function of the sideslip $(\beta)$ and the slip ratio $(\lambda)$.

where $\varpi=70 \mathrm{rad} / \mathrm{s}$ is the actuator cut-off frequency. $T_{b_{i j}}^{0}$ and $T_{b_{i j}}$ are the braking controller and actuator outputs, respectively. In this paper, only the rear braking system is used to avoid coupling phenomena occurring with the steering system.

- The active suspension systems are modelled as:

$$
\dot{F}_{\text {susp }_{i j}}=\tau\left(F_{\text {susp }_{i j}}^{0}-F_{\text {susp }_{i j}}\right)
$$

where $\tau=200 \mathrm{rad} / \mathrm{s}$ is the actuator cut-off frequency. $F_{s u s p_{i j}}^{0}$ and $F_{s u s p_{i j}}$ are the output of the suspension controller and actuator outputs, respectively. 


\subsection{Model remarks}

The main interest in using the full vehicle model is that it allows to take into consideration nonlinear load transfers, slipping and sideslip angles, that are essential phenomena entering in the tire force, and consequently, in the global chassis dynamics. When dangerous and critical driving situations are under investigation, these dynamics have to be clearly captured by the model.

The aforementioned model will be used in Section 4 for validation purpose. The passive reference model corresponds to the configuration where $u_{i j}=0$ and $T_{b_{i j}}=0$ (i.e., no suspension and no brake control).

\section{Main result: Suspension \& Brake controller design}

\subsection{General structure}

As illustrated on Figure 1, the main idea of the proposed structure is to design two controllers: one for the four suspensions and one for the rear braking systems. The coupling effects (i.e. interactions between the two controllers) are handled through two tuning parameters provided by the monitor. To design the two controllers, the full vehicle model dynamics is split into two separate models:

(i) Vertical model - used to synthesize the suspension controller: this model is usually used when comfort specifications and road-holding in normal cruise situations are to be considered. Denoted $\Sigma_{v e r t}$, it is obtained by linearising $\ddot{z}_{s}, \ddot{\theta}, \ddot{\phi}$ and $\ddot{z}_{u s_{i j}}$ of (1). The resulting model is given by:

$$
\Sigma_{v e r t}:\left\{\begin{array}{l}
\dot{x}_{v e r t}=A_{x} x_{v e r t}+B_{w} w_{v e r t}+B_{u} u_{v e r t} \\
y_{v e r t}=C_{y} x_{v e r t}+D_{y w} w_{v e r t}+D_{y u} u_{v e r t}
\end{array}\right.
$$

where,

$$
\begin{aligned}
& x_{v e r t}=\left[\begin{array}{ll}
x_{v} & \dot{x}_{v}
\end{array}\right]^{T}, x_{v}=\left[\begin{array}{lll}
z_{s} & z_{u s_{i j}} & \theta
\end{array}\right]^{T} \\
& w_{\text {vert }}=\left[\begin{array}{lll}
z_{r_{i j}} & F_{d x, y, z} & M_{d x, y}
\end{array}\right]^{T} \\
& u_{\text {vert }}=u_{i j} \\
& y_{\text {vert }}=z_{d e f_{i j}}
\end{aligned}
$$

(ii) Lateral model - used to synthesize the rear brake controller: This model is a simple extension of the classical bicycle model, which is classically used when yaw control and handling are studied. Denoted $\Sigma_{l a t}$, it is obtained by linearising $\dot{v}_{y}, \ddot{\psi}$ and $\dot{\beta}_{\text {cog }}$ of (1), for a given nominal longitudinal velocity. It is given by:

$$
\Sigma_{l a t}:\left\{\begin{array}{l}
\dot{x}_{l a t}=A_{x} x_{l a t}+B_{w} w_{l a t}+B_{u} u_{l a t} \\
y_{l a t}=C_{y} x_{l a t}+D_{y w} w_{l a t}+D_{y u} u_{l a t}
\end{array}\right.
$$

where, 


$$
\begin{aligned}
x_{l a t} & =\left[\begin{array}{ll}
x_{l} & \dot{x}_{b}
\end{array}\right]^{T}, x_{l}=\left[\begin{array}{lll}
\psi & \beta & v_{y}
\end{array}\right]^{T} \\
w_{\text {lat }} & =\left[\begin{array}{ll}
\delta & M_{d z}
\end{array}\right]^{T} \\
u_{\text {lat }} & =T_{b_{r j}} \\
y_{\text {lat }} & =\dot{\psi}
\end{aligned}
$$

Then, for each model, a controller has to be synthesized: the first is an active suspension and the second one is a rear braking system controller. As the two controllers performance objectives might vary, according to the driving situations (normal, emergency, critical), these controllers are designed using LPV methods. The link between the two models and the performance compromise is achieved thanks to the monitor.

This latter provides two parameters: (i) $R_{b}$, for the braking controller and (ii) $R_{s}$, for the suspension one. The aim of this monitor is to modify the two controller performances according to the degree of emergency. This modification is achieved through the gainscheduling (or LPV) approach. On Figure 1, the two monitor output parameters $R_{b}$ and $R_{s}$, are associated to $K_{\text {brake }}$ and $K_{\text {susp }}$, respectively.

\subsection{Monitor description}

The aim of the monitor is to provide the suspension and the braking controllers with a parameter standing for the driving situation in order to overcome conflicts of the objectives of the two controllers and to achieve well-coordinated action. The monitor provides:

(i) The Braking parameter $R_{b}=\min _{j=l, r}\left(r_{b_{j}}\right)$, a function of the absolute value of the rear slip ratio, $\left|\lambda_{r j}\right|$. Where $r_{b_{j}}$ is defined as a relay function delimiting the three main zones of the braking force (see Figure 4):

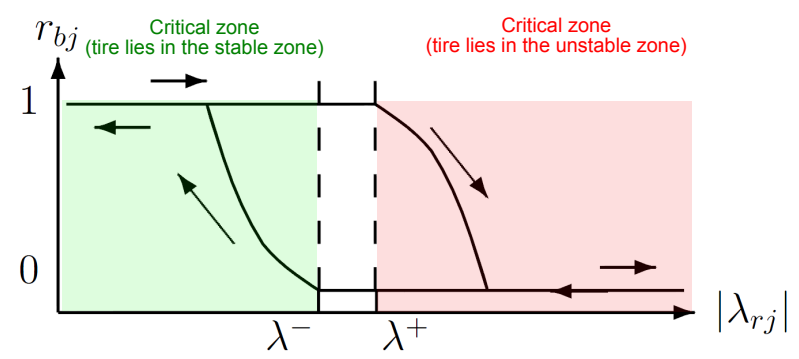

Fig. 4. $r_{b j}$ as a function of the rear slip $\left|\lambda_{r j}\right|$.

- when slip is low $\left(\lambda<\lambda^{-}\right)$, the braking force is in the stable zone of the longitudinal tire characteristics, i.e. linear zone of Figure 2, hence $R_{b} \rightarrow 1$ (left area of Figure 4). In this configurations, slip dynamics is stable.

- when the slip ratio raises (such that $\lambda>\lambda^{+}$), the slip dynamics enters the critical tire zone (decreasing slope of Figure 2), then $R_{b} \rightarrow 0$ (right area of Figure 4). At this moment, the slip dynamics is unstable and wheel tends to lock.

- from a high slip situation, when the slip value decreases and becomes lower than $\lambda^{-}$, tire comes back to the linear zone and wheel is no longer locked, $R_{b} \rightarrow 1$. 
The $\left\{\lambda^{-}, \lambda^{+}\right\}$couple parametrizes the $R_{b}$ behaviour and aims at detecting when the slip enters the unstable zone. Section 3.3 illustrates how this coefficient is used in the control scheme to avoid wheel locking. For numerical simulations, the threshold couple is select as: $\left\{\lambda^{-}, \lambda^{+}\right\}=\{0.08,0.1\}$.

(ii) The suspension monitor $R_{s}$ is simply a function of the $R_{b}$ parameter, defined as:

$$
R_{s}:= \begin{cases}1 & \text { if } 1>R_{b}>R_{\text {crit }}^{2} \text { (comfort) } \\ \frac{R_{b}-R_{c r i t}^{1}}{R_{c r i t}^{2}-R_{c r i t}^{1}} & \text { if } R_{\text {crit }}^{1}<R_{b}<R_{\text {crit }}^{2} \\ 0 & \text { if } 0<R_{b}<R_{\text {crit }}^{1} \text { (safety) }\end{cases}
$$

- when $R_{b}>R_{c r i t}^{2}$, i.e. when low slip is detected $\left(\lambda<\lambda^{-}\right)$, the vehicle is in classical situation; comfort is preferred.

- when $R_{b}<R_{c r i t}^{1}$, i.e. when high slip is detected $\left(\lambda>\lambda^{+}\right)$, the vehicle is in a critical situation; safety is preferred.

- intermediate values of $R_{b}$ give intermediate driving situations.

Section 3.4 shows how the suspension control performances will vary according to this parameter, focussing on comfort when $R_{s}=1$ and on road-holding when $R_{s}=0$. For numerical simulations, the threshold couple is select as: $\left\{R_{\text {crit }}^{1}, R_{\text {crit }}^{2}\right\}=$ $\{0.7,0.9\}$.

In the following subsections, both controllers are computed using the LPV $/ \mathcal{H}_{\infty}$ methodology in order to meet the varying performance objectives. The LPV design makes it possible to smoothly change control performances thanks to $R_{b}$ and $R_{s}$ parameters adaptation, while guaranteeing internal stability and minimizing the $\mathcal{L}_{2}$ to $\mathcal{L}_{2}$ norm of the transfer from exogenous inputs to controlled outputs. First, both braking and suspension LPV generalized problem are presented in Sections 3.3 and 3.4. Secondly, since the problem resolution is similar for both controllers, the LMI-based control synthesis is recalled in Section 3.5 for the dynamical output feedback case with one single parameter dependency.

\subsection{Problem formulation for the design of the Braking controller}

The braking system aims at improving handling, avoiding emergency situations such as yaw rate error and large lateral accelerations. One of the main challenging task in braking control is to provide an optimal force with respect to the nonlinear tire characteristics. Here, this problem is tackled in an original manner using the LPV $/ \mathcal{H}_{\infty}$ design methodology. Indeed, the varying parameter is the brake monitor $R_{b}$, acting on the weighting filters. As suggested in the monitor section, $R_{b}$ aims at ensuring that the required braking force remains in the linear stable zone of the tire characteristic and close to the maximal braking force. For this purpose, the following generalized control plant (used for control design purpose), including the weight functions, the exogenous inputs $\left(\dot{\psi}_{r e f}(v)-\dot{\psi}\right.$ and $\left.M_{d z}\right)$ and controlled outputs $\left(z_{1}\right.$ and $\left.z_{2}\right)$, is illustrated on Figure 5:

- Let $W_{e_{\dot{\psi}}}$, describing the yaw rate error performance (reference being provided by a nonlinear undisturbed bicycle model), be given as:

$$
W_{e_{\dot{\psi}}}=\frac{1}{k G_{e}} \frac{G_{e} s / w_{1}+1}{s / w_{1}+1}
$$




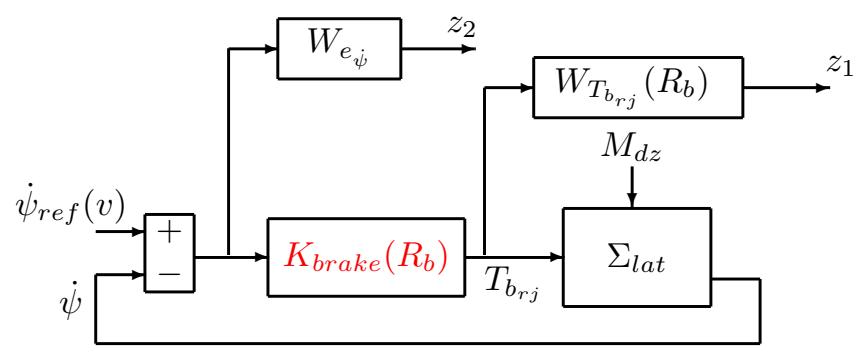

Fig. 5. Braking system generalized plant.

where $w_{1}=2 \pi f_{1}$, with $f_{1}=1 \mathrm{~Hz}$ is the tracking error performance cut-off frequency, $G_{e}$ is the steady-state tolerated error. In this case, $G_{e}=0.1$, which means that below $f_{1}$, the tracking yaw rate error must be lower than $10 \%$, and over $f_{1}$, error gain amplification is bounded by $k=2$ (allowing for a modulus margin below than 0.5 ).

- Let $W_{T_{b_{r j}}}\left(R_{b}\right)$ be a parameter dependent weight, acting on the controller gain, defined as:

$$
W_{T_{b_{r j}}}\left(R_{b}\right)=\left(1-R_{b}\right) \frac{s / \varpi+1}{s / 100 \varpi+1}
$$

where $\varpi$ is the braking actuator cut-off frequency.

- when $R_{b} \rightarrow 1$, the weighting function gain is low, hence the braking control signal gain will be allowed. Therefore, the braking action is activated.

- conversely, when $R_{b} \rightarrow 0$, the slip ratio is higher and might enter the unstable tire zone. Consequently, the weighting function gain is high, leading to the deactivation of the braking signal, therefore, a natural stabilisation of the slip dynamic (until $R_{b}$ comes back to 1$)$.

When the slip ratio $(\lambda)$ becomes too high, this mechanism will lead to bring it back to lower values. As the $R_{b}$ parameter is varying in an hysteresis way, the slip ratio will be "trapped" between $\lambda^{-}$and $\lambda^{+}$when high torque is required, guaranteeing good braking and avoiding slipping, reproducing the ABS principle (see Section 4).

Remark 1 : About the nonlinear tire characteristics

Since the controller design is done on a linear model, when high braking is applied, the model is no longer representative of the real road/tire friction. As a matter of fact, the $R_{b}$ monitoring step is essential to obtain good braking performances and to avoid slip dynamics increase.

Finally, with reference to $\Sigma_{l a t}$, weight functions defined above and interconnection given on Figure 5, the following parameter dependent brake generalized plant $\left(\Sigma_{g l}\left(R_{b}\right)\right)$ is obtained:

$$
\Sigma_{g l}\left(R_{b}\right):\left\{\begin{array}{l}
\dot{\xi}=A\left(R_{b}\right) \xi+B_{1} \tilde{w}+B_{2} u \\
\tilde{z}=C_{1} \xi+D_{11} \tilde{w}+D_{12} u \\
y=C_{2} \xi+D_{21} \tilde{w}+D_{22} u
\end{array}\right.
$$

where, 


$$
\begin{aligned}
\xi & =\left[x_{l a t} x_{w l}\right]^{T} \\
\tilde{z} & =\left[z_{1} z_{2}\right]^{T} \\
\tilde{w} & =M_{d z} \\
y & =\dot{\psi}_{r e f}(v)-\dot{\psi} \\
u & =T_{b_{r j}}
\end{aligned}
$$

where $x_{w l}$ are the states associated with the lateral weighting filters (i.e. $W_{e_{\psi}}$ and $\left.W_{T_{b_{r j}}}\left(R_{b}\right)\right)$. This aforementioned generalized model is used for the LPV $/ \mathcal{H}_{\infty}$ controller design.

\subsection{Problem formulation for the design of the Suspension controller}

Similarly to the braking controller, attitude control is ensured through suspension system (Sammier et al. 2003). The generalized control plant, including the weight functions, the exogenous inputs $\left(z_{r_{i j}}, F_{d x, y, z}\right.$ and $\left.M_{d x, y}\right)$ and controlled outputs $\left(z_{1}, z_{2}\right.$ and $\left.z_{3}\right)$, is illustrated on Figure 6:

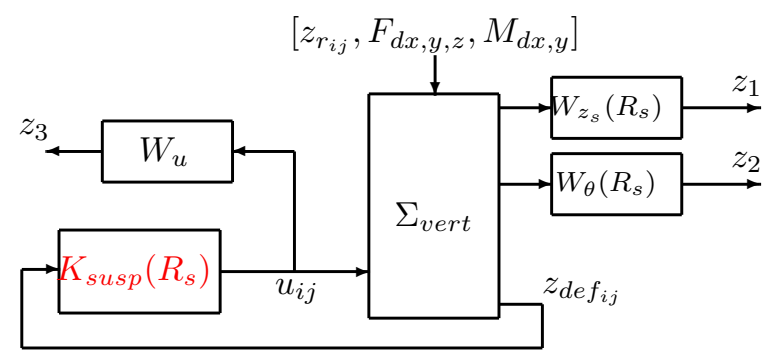

Fig. 6. Suspension system generalized plant.

With reference to Figure 6, the performances are defined through the following filters:

- Let define $W_{z_{s}}\left(R_{s}\right)$ as:

$$
W_{z_{s}}\left(R_{s}\right)=R_{s} \frac{2}{s /\left(2 \pi f_{1}\right)+1}
$$

defining the performance of the suspended mass $\left(z_{s}\right)$, shaped to reduce bounce amplification up to $10 \mathrm{~Hz}\left(f_{1}=10 \mathrm{~Hz}\right)$. When $R_{s} \rightarrow 1$, the control focusses on $z_{s}$ attenuation, i.e. on comfort objective.

- Let $W_{\theta}\left(R_{s}\right)$ be the performance filter acting on the roll, be defined as:

$$
W_{\theta}\left(R_{s}\right)=\left(1-R_{s}\right) \frac{2}{s /\left(2 \pi f_{2}\right)+1}
$$

where, $f_{2}=2 \mathrm{~Hz}$. When $R_{s} \rightarrow 0$, amplification in low frequencies and the frequency peak at $9 \mathrm{~Hz}$ aims to be filtered, leading to safety enhancement.

- Let $W_{u_{i j}}$ be defined as:

$$
W_{u_{i j}}=10^{-2}
$$

used, to limit the control signal amplification. The coefficient depends on the considered actuator gain. 
Finally, the complete suspension control law is then given as:

$$
u_{i j}=c_{j}^{0}\left(1-R_{s}\right)+u_{i j}^{\mathcal{H}_{\infty}}
$$

where $u_{i j}^{\mathcal{H}}$ is obtained by the LPV $/ \mathcal{H}_{\infty}$ design and $c_{j}^{0}$ is the nominal damping factor at front and rear positions of the vehicle $\left(c_{f}^{0}=700 \mathrm{~N} / \mathrm{m} / \mathrm{s}\right.$ and $\left.c_{r}^{0}=1400 \mathrm{~N} / \mathrm{m} / \mathrm{s}\right)$.

Then, accordingly to the parametrized weight functions and the complete control law in (21), it turns that, when the braking is in the linear zone (tire stable zone, i.e. $R_{s} \rightarrow 1$ ), suspensions are tuned to improve comfort. Consequently, nominal damping $c_{j}^{0}$ is scaled to be low and weighting function aims at filtering chassis heave amplifications. So it is conversely.

Finally, with reference to $\Sigma_{v e r t}$, weight functions defined above and interconnection given on Figure 6 , the following parameter dependent suspension generalized plant $\left(\Sigma_{g v}\left(R_{s}\right)\right)$ is obtained:

$$
\Sigma_{g v}\left(R_{s}\right):\left\{\begin{array}{l}
\dot{\xi}=A\left(R_{s}\right) \xi+B_{1} \tilde{w}+B_{2} u \\
\tilde{z}=C_{1} \xi+D_{11} \tilde{w}+D_{12} u \\
y=C_{2} \xi+D_{21} \tilde{w}+D_{22} u
\end{array}\right.
$$

where,

$$
\begin{aligned}
& \xi=\left[x_{v e r t} x_{w v}\right]^{T} \\
& \tilde{z}=\left[\begin{array}{lll}
z_{1} & z_{2} & z_{3}
\end{array}\right]^{T} \\
& \tilde{w}=\left[\begin{array}{lll}
z_{r_{i j}} & F_{d x, y, z} & M_{d x, y}
\end{array}\right]^{T} \\
& y=z_{d e f_{i j}} \\
& u=u_{i j}
\end{aligned}
$$

where $x_{w v}$ are the states associated with the vertical weighting filters. This latter generalized model is used for the LPV $/ \mathcal{H}_{\infty}$ controller design.

\subsection{LMI-based Brake and Suspension controller synthesis}

With reference to the two generalized models (16) and (22), the associated LPV controllers are obtained through the same resolution. Here, the LMI-based resolution is done with YALMIP parser (Lofberg 2004) and SeDuMi solver (Sturm 1999). In this case, we seek for two dynamical output feedback controllers $\left(K_{\text {brake }}\right.$ and $\left.K_{\text {susp }}\right)$, dependent on a scheduling parameter $\left(R_{b}\right.$ or $\left.R_{s}\right)$, achieving $\mathcal{H}_{\infty}$ closed-loop performances. The solution of this LPV $/ \mathcal{H}_{\infty}$ problem is briefly recalled here. Since the resolution is similar for both cases, let denote $\Sigma_{g}$ the generalized plant (i.e. either $\Sigma_{g l}$ or $\Sigma_{g v}$ ) and $R$, the varying parameter (i.e. either $R_{b}$ or $R_{s}$ ).

In the $\mathcal{H}_{\infty}$ approach, the control synthesis relies on a disturbance attenuation problem. It consists in finding a stabilizing controller that minimizes the impact of the input disturbances $\tilde{w}(t)$ on the controlled output $\tilde{z}(t)$. In the case of the LPV $/ \mathcal{H}_{\infty}$ control, this impact must be measured thanks to the induced $\mathcal{L}_{2}-\mathcal{L}_{2}$ norm, which is referred to as a $\mathcal{H}_{\infty}$ problem and is represented in Figure 7 . On Figure $7, W_{i}=I_{n_{\tilde{w}}}\left(n_{\tilde{w}}\right.$ is the number of exogenous inputs) is the input filter and $W_{o}(R)=\operatorname{diag}\left(W_{e_{\psi}}, W_{T_{b_{r j}}}\left(R_{b}\right)\right)$ 
(brake controller design case) or $W_{o}(R)=\operatorname{diag}\left(W_{z_{s}}\left(R_{s}\right), W_{\theta}\left(R_{s}\right), W_{u_{i j}}\right)$ (suspension controller design case).

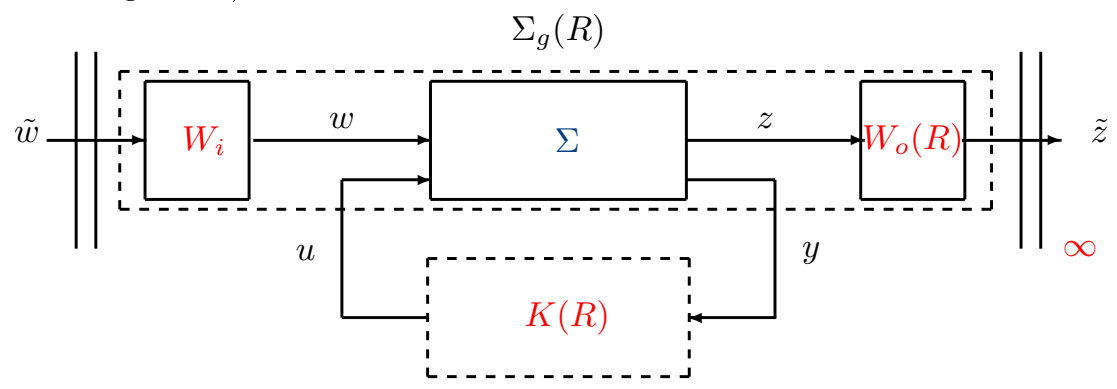

Fig. 7. Generalized $\mathcal{H}_{\infty}$ control scheme.

The $\mathcal{H}_{\infty}$ control synthesis solution for LPV systems is extended from the LTI one. Both following propositions solve the $\mathrm{LPV} / \mathcal{H}_{\infty}$ problem using a polytopic approach for one single varying parameter. The first one is related to the feasibility, and the second one, to the controller reconstruction (Scherer et al. 1997).

Proposition $1: L P V / \mathcal{H}_{\infty}$ feasibility

Let consider the interconnection in Figure 7 , where $\Sigma_{g}(R)$ is defined by the state space representation given in (16) or (22). There exists a full order dynamical output feedback controller of the form,

$$
K(R):\left\{\begin{aligned}
\dot{x}_{c}(t) & =A_{c}(R) x_{c}(t)+B_{c}(R) y(t) \\
u(t) & =C_{c}(R) x_{c}(t)
\end{aligned}\right.
$$

minimizing the LPV polytopic $\mathcal{H}_{\infty}$ norm if there exist symmetric matrices $X, Y \in \mathbb{R}^{n \times n}$, and matrices $\widetilde{\mathbf{A}}(\underline{R}), \widetilde{\mathbf{A}}(\bar{R}) \in \mathbb{R}^{n \times n}, \widetilde{\mathbf{B}}(\underline{R}), \widetilde{\mathbf{B}}(\bar{R}) \in \mathbb{R}^{n \times n_{u}}, \widetilde{\mathbf{C}}(\underline{R}), \widetilde{\mathbf{C}}(\bar{R}) \in \mathbb{R}^{n_{y} \times n}$ and $\gamma \in$ $\mathbb{R}^{+*}$ that are solutions to the following problem (where $n, n_{u}$ and $n_{y}$ are the column number of $A, B_{2}$ and $C_{2}^{T}$, respectively):

$$
\gamma^{*}=\min \gamma
$$

$$
\left[\begin{array}{cccc}
\underline{H}_{11}+\underline{H}_{11}^{T} & (\star)^{T} & (\star)^{T} & (\star)^{T} \\
\widetilde{\mathbf{A}}(\underline{R})+A(\underline{R})^{T} & \underline{H}_{22}+\underline{H}_{22}^{T} & (\star)^{T} & (\star)^{T} \\
B_{1}^{T} & B_{1}^{T} \mathbf{Y}+D_{21}^{T} \widetilde{\mathbf{B}}(\underline{R})^{T} & -\gamma I_{n_{w}} & (\star)^{T} \\
C_{1} \mathbf{X}+D_{12} \widetilde{\mathbf{C}}(\underline{R}) & C_{1} & D_{11} & -\gamma I_{n_{z}} \\
\bar{H}_{11}+\bar{H}_{11}^{T} & (\star)^{T} & (\star)^{T} & (\star)^{T} \\
\widetilde{\mathbf{A}}(\bar{R})+A(\bar{R})^{T} & \bar{H}_{22}+\bar{H}_{22}^{T} & (\star)^{T} & (\star)^{T} \\
B_{1}^{T} & B_{1}^{T} \mathbf{Y}+D_{21}^{T} \widetilde{\mathbf{B}}(\bar{R})^{T} & -\gamma I_{n_{w}} & (\star)^{T} \\
C_{1} \mathbf{X}+D_{12} \widetilde{\mathbf{C}}(\bar{R}) & C_{1} & D_{11} & -\gamma I_{n_{z}}
\end{array}\right] \prec 0
$$


with $\underline{H}_{11}=A(\underline{R}) \mathbf{X}+B_{2} \widetilde{\widetilde{\mathbf{C}}}(\underline{R}), \underline{H}_{22}=\mathbf{Y} A(\underline{R})+\widetilde{\mathbf{B}}(\underline{R}) C_{2}, \bar{H}_{11}=A(\bar{R}) \mathbf{X}+B_{2} \widetilde{\mathbf{C}}(\bar{R})$ and $\bar{H}_{22}=\mathbf{Y} A(\bar{R})+\widetilde{\mathbf{B}}(\bar{R}) C_{2}$. Moreover, $n_{w}$ and $n_{z}$ are the column number of $B_{1}$ and $C_{1}$, respectively.

$$
\left[\begin{array}{cc}
\mathbf{X} & I \\
I & \mathbf{Y}
\end{array}\right] \succ 0
$$

Proposition $2: L P V / \mathcal{H}_{\infty}$ reconstruction

If such a controller $K(R)$ exists (feasibility Proposition 1 satisfied), the controller reconstruction is obtained by solving the following system of equations at each vertex of the polytope, i.e.:

$$
\begin{array}{r}
\text { solve (29) }\left.\right|_{R=\underline{R}} \\
\text { (29) }\left.\right|_{R=\bar{R}}
\end{array}
$$

$$
\left\{\begin{array}{l}
C_{c}(R)=\widetilde{C}(R) M^{-T} \\
B_{c}(R)=N^{-1} \widetilde{B}(R) \\
A_{c}(R)=N^{-1}\left(\widetilde{A}(R)-Y A X-N B_{c}(R) C_{2} X-Y B_{2} C_{c}(R) M^{-T}\right) M^{-T}
\end{array}\right.
$$

where $M$ and $N$ are defined such that $M N^{T}=I-X Y$ which are chosen by applying a singular value decomposition and a Cholesky factorization, as follows:

(i) Singular value decomposition: $I-X Y=U \Sigma V^{T}$

(ii) Cholesky factorization: $\Sigma=R^{T} R$

(iii) Then one can choose, $M=U R^{T}$ and $N=V R^{T}$

For more details on the LMI, the reader is invited to refer to the contributive work of Scherer et al. (1997). Proofs and comments are also provided in Poussot-Vassal (2008)'s Ph.D. thesis.

Remark 2 : Numerical issues

Practically, LMIs (26) should be solved a first time to find $\gamma^{*}$, the optimal attenuation level, then a second time by fixing the attenuation level $\gamma=\gamma^{*}(1+\nu / 100)$, where $\nu>0$. In this second step, inequality (27) is replaced by,

$$
\left[\begin{array}{cc}
X & \alpha I \\
\alpha I & Y
\end{array}\right] \succ 0
$$

where $\alpha>0$. Then, the optimization consists in maximizing $\alpha$. This procedure maximizes the minimal eigenvalue of $X Y$, in order to be pushed away from $I$. This avoids a bad conditioning when inverting $M$ and $N$ in the controller reconstruction step.

\subsection{Synthesis results}

By applying Proposition 1 and 2 to the brake and suspension generalized plants, two parameter dependent controllers are obtained. The suspension control law is thus: 


$$
\left\{\begin{aligned}
u_{i j} & =c_{j}^{0}\left(1-R_{s}\right)+u_{i j}^{\mathcal{H}}\left(R_{s}\right) \\
u_{i j}^{\mathcal{H} \infty}\left(R_{s}\right) & =\left[\frac{\left|R_{s}-\overline{R_{s}}\right|}{\overline{R_{s}}-\underline{R_{s}}} K_{s}\left(\underline{R_{s}}\right)+\frac{\left|R_{s}-\underline{R_{s}}\right|}{\overline{R_{s}}-\underline{R_{s}}} K_{s}\left(\overline{R_{s}}\right)\right] z_{\text {def }}
\end{aligned}\right.
$$

where $K_{s}\left(\underline{R_{s}}\right)$ and $K_{s}\left(\overline{R_{s}}\right)$ are the controller solution of the LMI based polytopic problem. Similarly, the braking control law is defined as:

$$
T_{b_{r j}}=\left[\frac{\left|R_{b}-\overline{R_{b}}\right|}{\overline{R_{b}}-\underline{R_{b}}} K_{b}\left(\underline{R_{b}}\right)+\frac{\left|R_{b}-\underline{R_{b}}\right|}{\overline{R_{b}}-\underline{R_{b}}} K_{b}\left(\overline{R_{b}}\right)\right]\left(\dot{\psi}_{r e f}(v)-\dot{\psi}\right)
$$

where $K_{b}\left(\underline{R_{b}}\right)$ and $K_{b}\left(\overline{R_{b}}\right)$ are the controller solving the LMI based polytopic problem.

\subsubsection{Suspension controller}

The suspension controller performances, for varying $R_{s}$ values, are shown on Figures 8 and 9. It illustrates the closed-loop Bode diagram for $R_{s} \in(0,1)$. It is worth noticing that attenuation of the transfer functions from $z_{r}$ to $z_{s}$ and $\ddot{z}_{s}$ implies comfort enhancement, and, conversely, that of the transfer functions from $z_{r}$ to $z_{u s}$ and $z_{\text {def }}$ provides roadholding improvement. Figure 8 illustrates that when $R_{s} \rightarrow 1$, the suspension tends to improve comfort while deteriorating road-holding (and reciprocally).
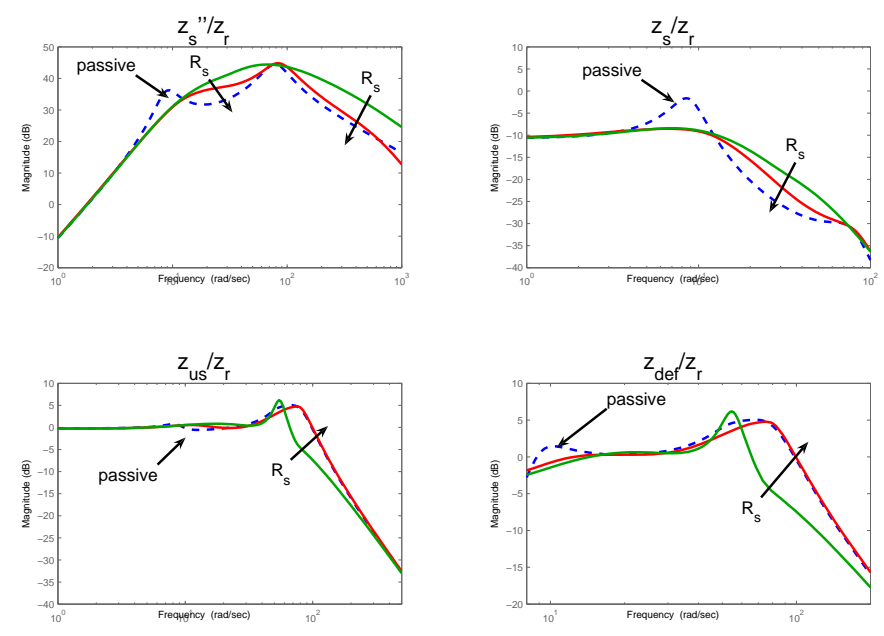

Fig. 8. From top left to bottom right: chassis vertical acceleration $\left(\ddot{z}_{s}\right)$, displacement $\left(z_{s}\right)$, wheel vertical displacement $\left(z_{u s}\right)$ and suspension deflection $\left(z_{\text {def }}\right)$ with respect to vertical road disturbance $\left(z_{r}\right)$. Passive response (blue dashed), Active response for varying $R_{s}$ values (solid).

Similarly, Figure 9 shows the results concerning the chassis attitude (roll and pitch) with respect to disturbing moments (e.g. caused by a braking or cornering action).

These Bode diagrams illustrates the fact that, a modification in the $R_{s}$ parameter induces a suspension control behaviour adaptation. 

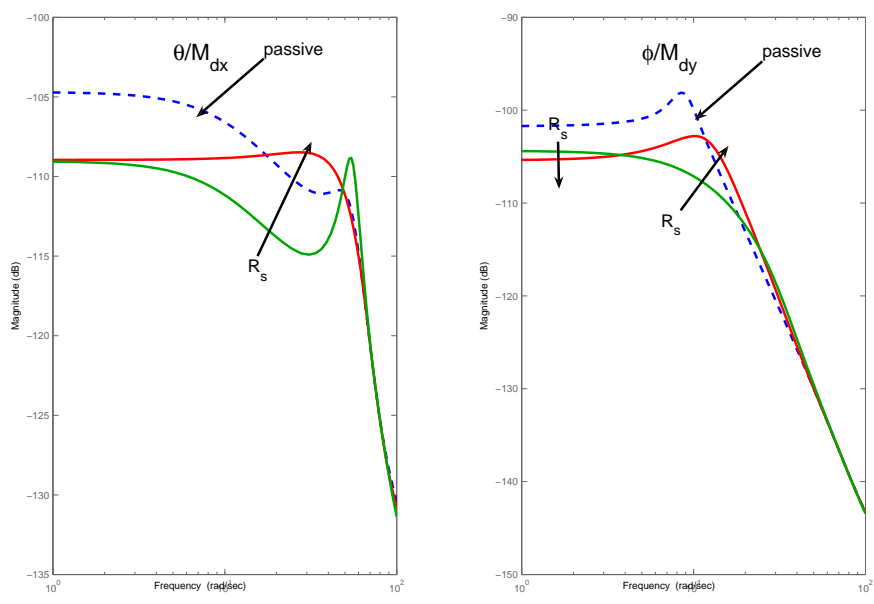

Fig. 9. Left: roll $(\theta)$ response to a x-axis disturbance moment $\left(M_{d x}\right)$. Right: pitch $(\phi)$ response to a y-axis disturbance moment $\left(M_{d y}\right)$. Passive response (blue dashed), Active response for varying $R_{s}$ values (solid).

\subsubsection{Braking controller}

In the braking controller design, the parameter dependency only affects the control signals (i.e. $\left.W_{T_{b_{r j}}}\left(R_{b}\right)\right)$. On Figure 10, it is shown how the Brake controller behaves according to $R_{b}$.

\section{Bode Diagram}

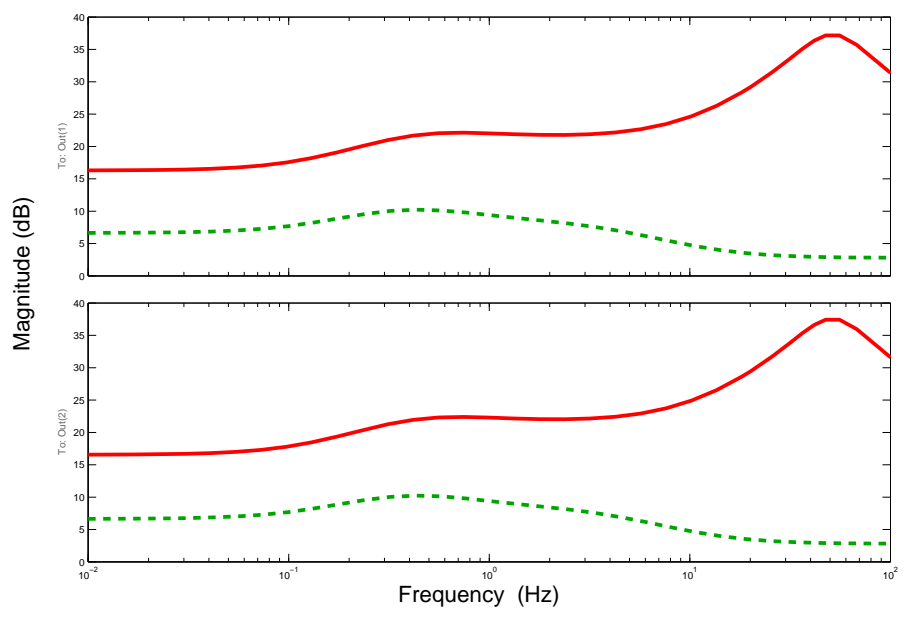

Fig. 10. Braking controller Bode from input $\left(\dot{\psi}_{r e f}(v)-\dot{\psi}\right)$ to outputs $\left(T_{b_{r l}}\right.$ and $\left.T_{b_{r r}}\right)$ as a function of the braking parameter $R_{b}$. Solid lines: $R_{b}=1$ parametrisation (brake activated); Dashed lines: $R_{b}=0$ parametrisation (brake deactivated).

Figure 10 clearly illustrates that when $R_{b} \rightarrow 1$ (when the slip ratio $\lambda$ is low), high 
braking torque is allowed, leading to the activation of the barking system. Conversely, when $R_{b} \rightarrow 0$, the braking torque is drastically limited. As a matter of fact (i) when the monitor detects low slip values, the controller is "active" $\left(R_{b}\right.$ high and control torque is allowed); (ii) when the monitor detects high slip values, the controller is de-activated. Consequently, the slip ratio naturally comes back to the stable safe zone, as it is expected.

\section{Simulation examples}

So far, the interest of the proposed method has been presented through the physical meaning of the $\mathcal{H}_{\infty}$ weighting filters. In this section, simulations are performed on the full nonlinear vehicle model given in Section 2, using the numerical values identified on a Renault Mégane Coupé. From now on, the performances obtained by the proposed gainscheduled controller, denoted as 'LPV', are analysed and compared to the uncontrolled Renault Mégane Coupé car, denoted as 'Passive' or 'Uncontrolled', and, for the sake of completeness, to a simple LTI $/ \mathcal{H}_{\infty}$ controller (synthesized with the same weighting filters, but with a frozen value $\left.\left\{R_{s}, R_{b}\right\}=\{1,1\}\right)$.

\subsection{Test 1: Double line change scenario}

The following scenario is simulated (see also Figure 11):

(i) Vehicle runs at $130 \mathrm{~km} / \mathrm{h}$ in straight line on a dry road.

(ii) A $5 \mathrm{~cm}$ bump on the left wheels (from $t=0.5 \mathrm{~s}$ to $t=1 \mathrm{~s}$ )

(iii) A double line change manoeuvre is performed (from $t=2 \mathrm{~s}$ to $t=6 \mathrm{~s}$ )

(iv) A lateral wind occurs at vehicle's front, generating an undesirable yaw moment (from $t=2.5 \mathrm{~s}$ to $t=3 \mathrm{~s}$ )

(v) $5 \mathrm{~cm}$ bump on the left wheels, during the manoeuvre (from $t=3 \mathrm{~s}$ to $t=3.5 \mathrm{~s}$ )
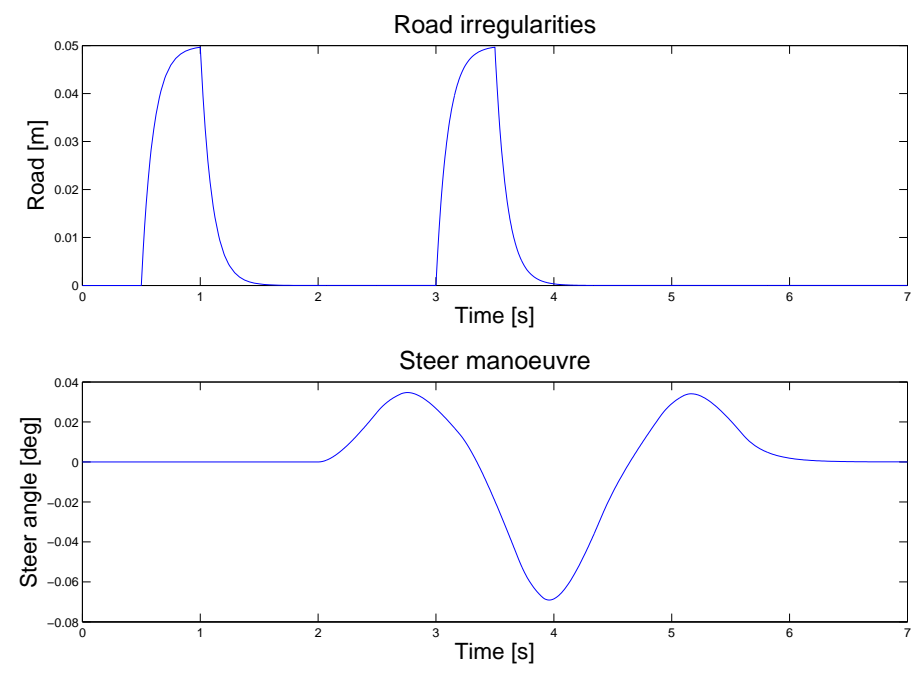

Fig. 11. Test 1: Input signals. Up: road disturbance $\left(z_{r}\right)$, down: steering angle $(\delta)$. 
Resulting to scenario 1, Figure 12 shows the obtained monitored signals, gathering the slip $(\lambda)$ with the $R_{b}$ and $R_{s}$ monitor output values.

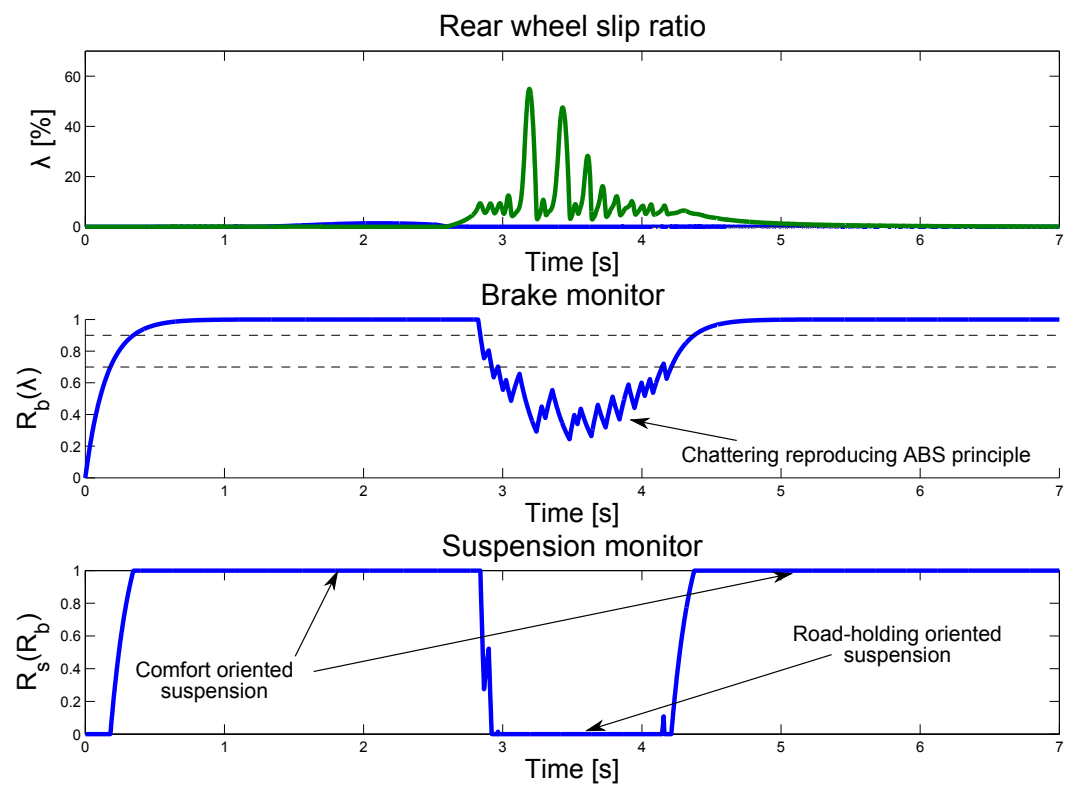

Fig. 12. Test 1: Rear slip ratio $\left(\lambda_{r j}\right) \&$ Monitored signals $\left(R_{b}\right.$ and $\left.R_{s}\right)$.

At the beginning of the experiment, the vehicle is in a safe situation; consequently the $R_{b}$ and $R_{s}$ parameters are set to one i.e. in comfort position.

At time $t=2.5 \mathrm{~s}$, the vehicle is subject to a positive yaw moment disturbance, leading to an undesirable yaw rate error. Consequently, the rear right wheel brake is activated to overcome the loss of trajectory and re-stabilize the vehicle. Since the required braking torque is very high, the slip ratio $(\lambda)$ rapidly raises.

Since the 'LTI controller' increases the braking force without handling the slip dynamics, the wheel locks and the brake force saturates (left frame of Figure 13 and 14). Conversely, thanks to the monitor detecting the slip increase, the $R_{b}$ parameter is decreased during all the braking duration to avoid locking and yielding to a better braking efficiency provided by the 'LPV controller' (see right frame of Figure 13 and 14).

This first result emphasizes the interest of the LPV structure for the braking control. Indeed, thanks to the braking parameter value $\left(R_{b}\right)$, reproducing the ABS principle, the vehicle using the gain-scheduled controller provides a braking force that stays close to the optimal zone avoiding the dangerous slipping phenomena, which is another contribution in this controller design. With reference to middle frame of Figure 12, it is interesting to note that $R_{b}$ chatters between $t=3 \mathrm{~s}$ and $t=4 \mathrm{~s}$, allowing for braking repetitive de-activation/re-activation. This mechanism is clearly recalls the ABS one.

Moreover, the interest of the LPV design is also present in the vehicle global behaviour and in the suspension adaptation to a "dangerous" situation, making the actuators collaborate. Indeed, in the same time period $(t=3 \mathrm{~s}$ to $t=4 \mathrm{~s})$, the $R_{s}$ parameter, associated to the suspension controller is set to $R_{s}=0$ in order to adjust the suspension system to 

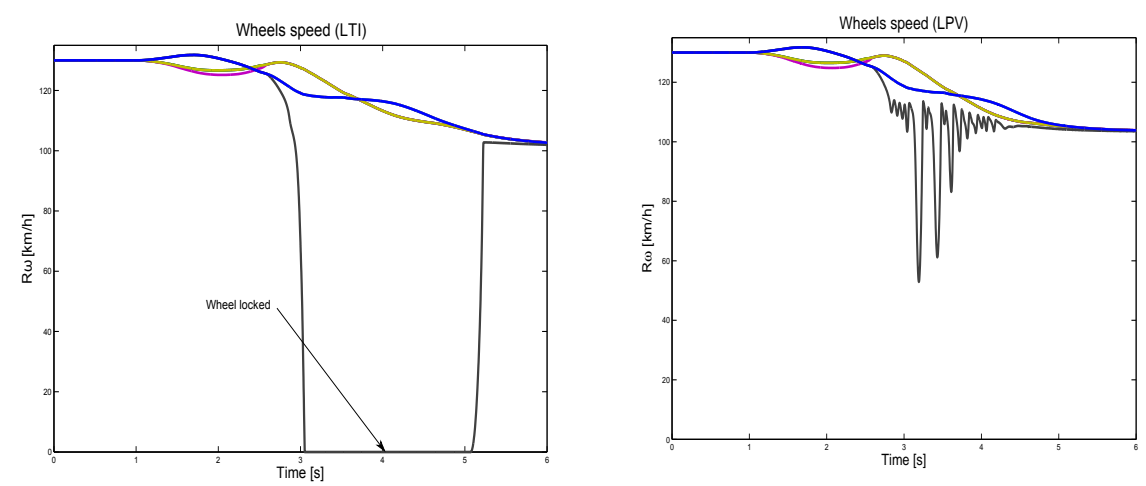

Fig. 13. Test 1: Four wheels rotational velocities. Left: LTI design, right: LPV design.
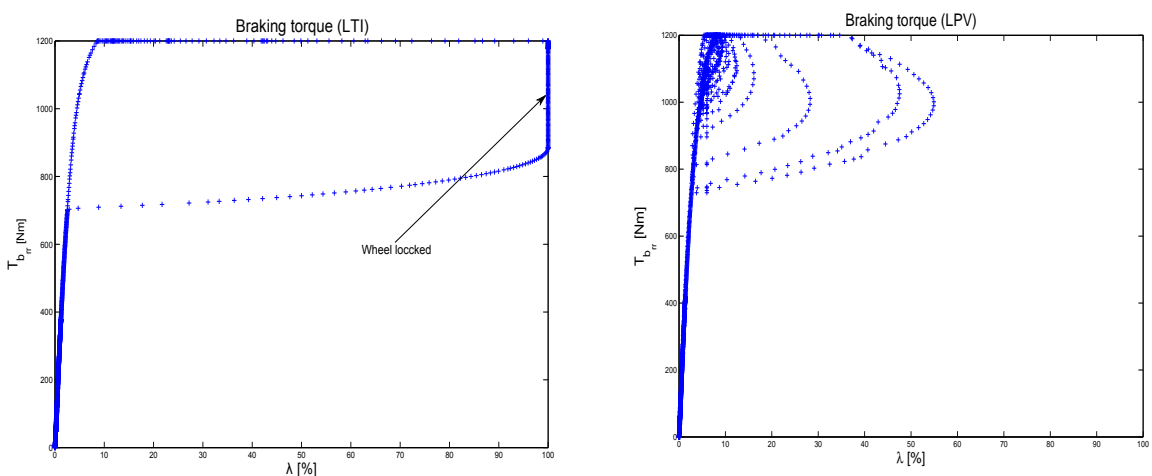

Fig. 14. Test 1: Rear right braking torque as a function of the wheel slip value. Left: LTI design, right: LPV design.

road-holding objective (see bottom frame of Figure 12). The vertical behaviour is given on Figure 15.

Considering the 'LPV controller', during the first bump, the vertical acceleration is much more reduced, than during the second one (while both bumps are of same amplitude). Actually, during the second road bump, the suspension controller focusses on road-holding, therefore, the vertical vehicle acceleration is not enhanced as much as during the first one. Note also that while the 'LTI controller' gives the same performances for the two bumps, the LPV one degrades its comfort performances during the critical driving phase in order to focus on road-holding (between $t=2 \mathrm{~s}$ and $t=4 \mathrm{~s}$ ). It results in a higher vertical acceleration of the suspended mass when the vehicle is in critical situation.

\subsection{Test 2: Vehicle stability analysis}

While the first example illustrates the suspension adaptation and the ABS principle, this second one focuses on handling enhancement. Here, let consider a double line change at $90 \mathrm{~km} / \mathrm{h}$ on an icy road. As previously, comparisons are made between the 'Passive 


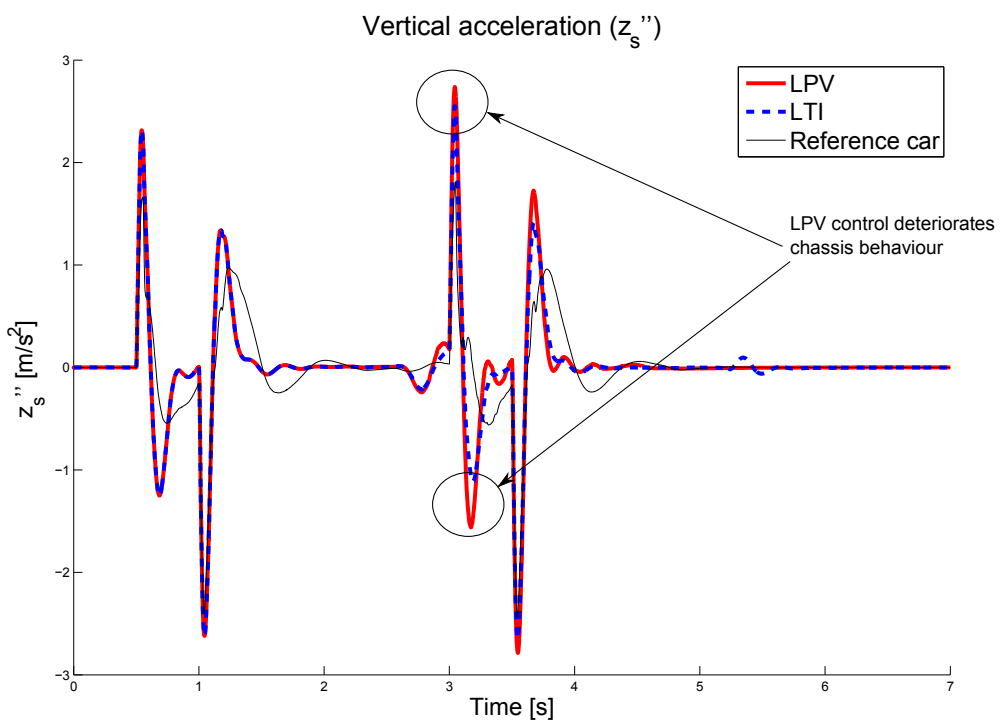

Fig. 15. Test 1: Vertical chassis acceleration $\left(\ddot{z}_{s}\right)$.

prime car', the 'LTI' and the 'LPV' control designs. Figure 16 compares the yaw rate $(\dot{\psi})$ and lateral velocity $\left(\dot{y}_{s}\right)$ dynamics for all the controllers. With reference to Figure 16, the following comments hold:

- the yaw rate tracking (top frame of Figure 16) is well done by the LPV control, while the LTI one clearly shows to become inefficient. This is due to the fact that the ground adherence is very low, hence the LTI controller quickly enters the slip instability and produces non appropriate braking torques, leading to wheel locking and potential vehicle skidding. Conversely, the LPV controller adapts its braking control thanks to the monitoring value.

- the same observation holds on the lateral velocity $\left(\dot{y}_{s}\right)$. The bottom frame of Figure 16 shows that the LTI controller implies high lateral velocities.

Finally, the wheel velocities and tire forces are shown on Figure 17 and 18, respectively. By comparing the braking and wheel velocities signals, plotted on Figure 17, one clearly see that the proposed LPV design handle the high nonlinearity introduced by the longitudinal tire characteristics, avoiding wheel locking phenomena. The 'LPV' strategy avoids skidding situation while the 'LTI' one leads actuators to saturation and slip instability. Additionally, loss of manoeuvrability is avoided thanks to slip indirect control.

\section{Conclusions}

In this paper, a global chassis strategy involving both active suspension and rear braking systems, is presented. The originality of the proposed design relies in the introduction of two parameters to handle the performance compromise, actuator efficiency and well-coordinated action. The proposed design handles the driving situation dependent objective in a unified way. 

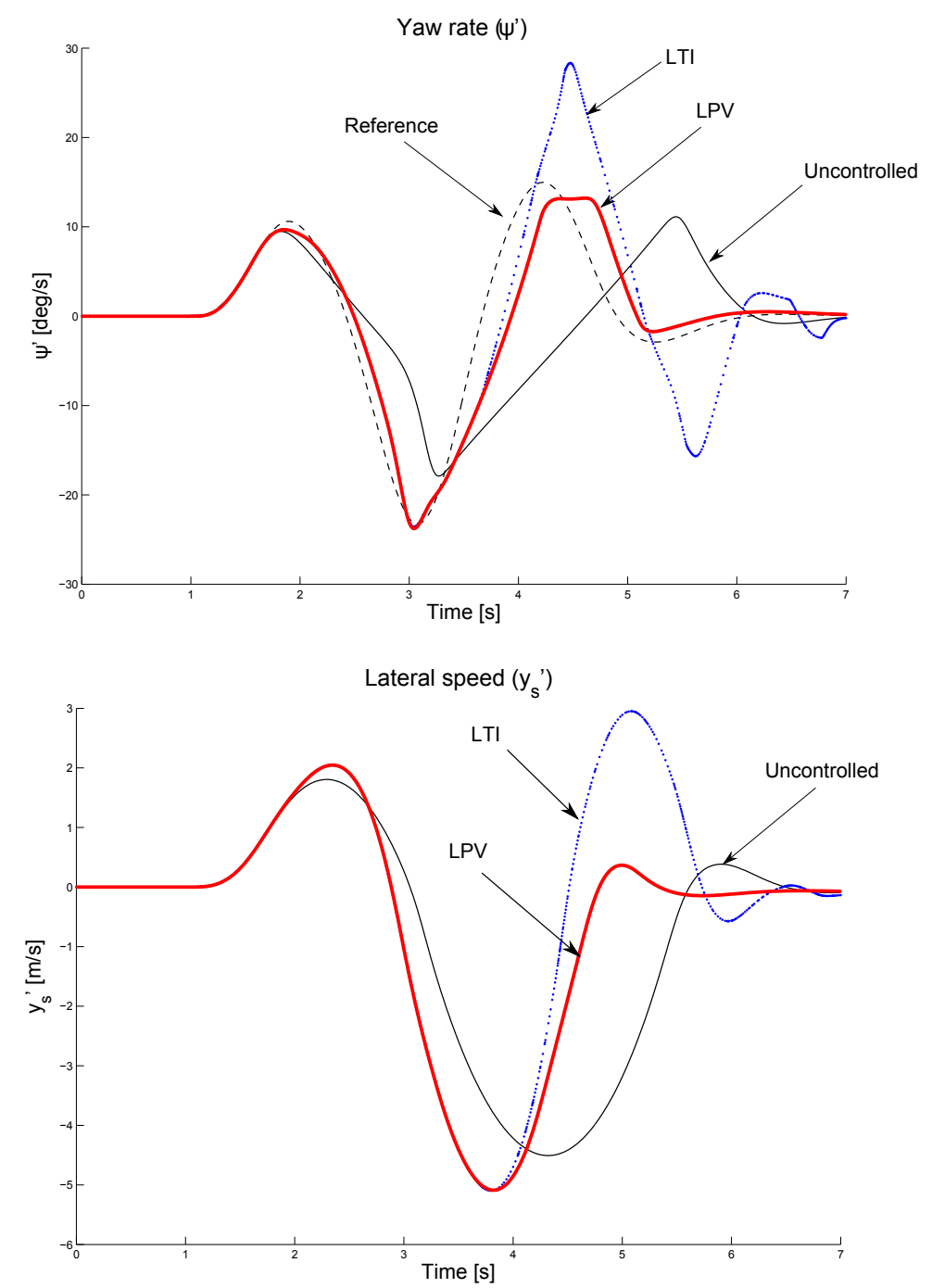

Fig. 16. Test 2: Vehicle yaw rate (up) and lateral velocity (down). Yaw rate reference (black, dashed), Reference model (solid thin), LTI controlled (dotted), LPV controlled (solid thick).

Both vehicle yaw stability and attitude are improved using the gain-scheduled robust methodology (adjusted with $\mathcal{H}_{\infty}$ criteria). Internal stability and effective actuator use, over a large driving situation, are ensured. The braking strategy, that reproduces the ABS working principle, is also designed in an original way, which is an other contribution of the paper. The authors stress that an advantage of such a method is that the exact knowledge of the tire force curve is not needed to guarantee good performances and keep vehicle stability, whatever the road condition.

Simulations of dangerous driving situations, performed on a complex nonlinear model (validated on real experimental data), have shown the effectiveness of the proposed struc- 

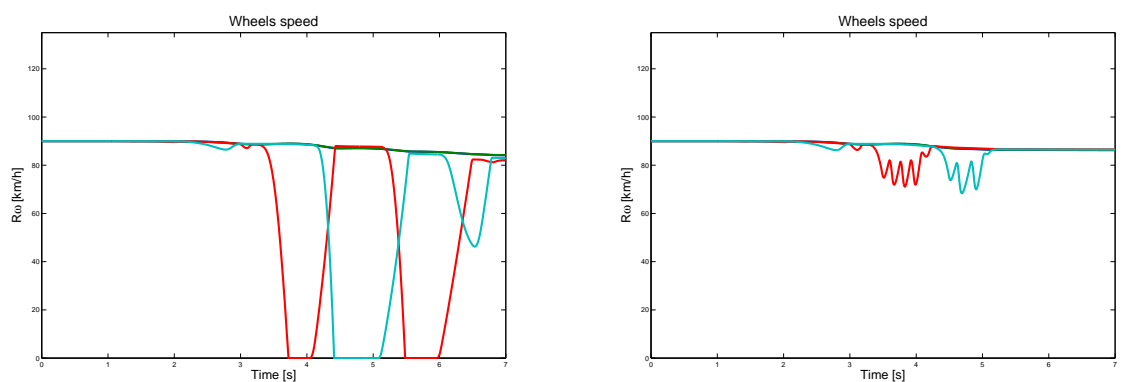

Fig. 17. Test 2: four wheels velocities. Left: LTI control strategy. Right: LPV control strategy.
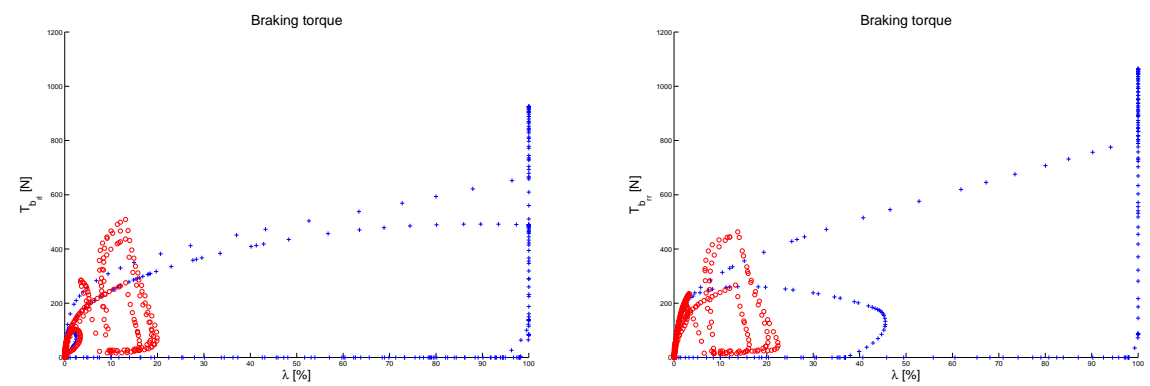

Fig. 18. Test 2: Left: braking torque (cross, LTI case / round, LPV case). Right: braking torque (cross, LTI case / round, LPV case).

ture.

Acknowledgements

Authors are very grateful to the Editor for helping in clarifying and improving the readability of the paper.

\section{References}

Biannic, J.M. (1996). Robust control of parameter varying systems: aerospace applications. Ph.D. thesis (in French). Université Paul Sabatier (ONERA), Toulouse, France.

Botero, J.C., M. Gobbi, G. Mastinu, R. Martorana and N.D. Piazza (2007). On the reformulation of the ABS logic by sensing forces and moments at the wheels. In: Proceedings of the 5th IFAC Symposium on Advances on Automotive Control (AAC). Aptos, California.

Bruzelius, F. (2004). Linear Parameter-Varying Systems: an approach to gain scheduling. Ph.D. thesis. University of Technology of Göteborg, Sweden.

Canale, M., L. Fagiano, M. Milanese and P. Borodani (2007). Robust vehicle yaw control using an active differential and IMC techniques. Control Engineering Practice 15(8), 923-941.

Canudas-de-Wit, C., E. Velenis, P. Tsiotras and G. Gissinger (2003). Dynamic tire friction models for road/tire longitudinal interaction. Vehicle System Dynamics 39(3), 189-226. 
Chou, H. and B. d'Andréa Novel (2005). Global vehicle control using differential braking torques and active suspension forces. Vehicle System Dynamics 43(4), 261-284.

Denny, M. (2005). The dynamics of antilock brake systems. European Journal of Physics 26, 1007-1016.

Gáspár, P., Z. Szabó, J. Bokor, C. Poussot-Vassal, O. Sename and L. Dugard (2007). Towards global chassis control by integrating the brake and suspension systems. In: Proceedings of the 5th IFAC Symposium on Advances in Automotive Control (A AC). Aptos, California, USA.

Gillespie, T.D. (1992). Fundamental of vehicle dynamics. Society of Automotive Engineers, Inc.

Kiencke, U. and L. Nielsen (2000). Automotive Control Systems.

Lofberg, J. (2004). YALMIP : A toolbox for modeling and optimization in matlab. In: Proceedings of the CACSD Conference. Taipei, Taiwan.

Poussot-Vassal, C. (2008). Robust Multivariable Linear Parameter Varying Automotive Global Chassis Control. Ph.D. thesis (in English). Grenoble INP, GIPSA-lab, Control System dpt., Grenoble, France.

Poussot-Vassal, C., O. Sename and L. Dugard (2008a). A global chassis controller for handling improvements involving braking and steering systems. In: Proceedings of the 4 7th IEEE Conference on Decision and Control (CDC). Cancun, Mexico.

Poussot-Vassal, C., O. Sename, L. Dugard, P. Gáspár, Z. Szabó and J. Bokor (2008b). Attitude and handling improvements through gain-scheduled suspensions and brakes control. In: Proceedings of the 17th IFAC World Congress (WC). Seoul, South Korea.

Poussot-Vassal, C., O. Sename, L. Dugard, P. Gáspár, Z. Szabó and J. Bokor (2008c). A New semi-active suspension control strategy through LPV technique. Control Engineering Practice 16(12), 15191534.

Sammier, D., O. Sename and L. Dugard (2003). Skyhook and $\mathcal{H}_{\infty}$ control of active vehicle suspensions: some practical aspects. Vehicle System Dynamics 39(4), 279-308.

Scherer, C., P. Gahinet and M. Chilali (1997). Multiobjective output-feedback control via LMI optimization. IEEE Transactions on Automatic Control 42(7), 896-911.

Sturm, Jos F. (1999). Using SeDuMi 1.02, a MATLAB toolbox for optimization over symmetric cones. Optim. Methods Softw. 11/12(1-4), 625-653.

Tanelli, M., R. Sartori and S.M. Savaresi (2007). Sliding mode slip-deceleration control for brake-by-wire control systems. In: Proceedings of the 5th IFAC Symposium on Advances on Automotive Control $(A A C)$. Aptos, California.

Velenis, E., P. Tsiotras, C. Canudas and M. Sorine (2005). Dynamic tire friction models for combined longitudinal and lateral vehicle motion. Vehicle System Dynamics 43(1), 3-29.

Zin, A. (2005). Robust automotive suspension control toward global chassis control. Ph.D. thesis (in french). INPG, Laboratoire d'Automatique de Grenoble (new GIPSA-lab), Grenoble, France.

Zin, A., O. Sename, P. Gaspar, L. Dugard and J.Bokor (2008). Robust LPV - $\mathcal{H}_{\infty}$ control for active suspensions with performance adaptation in view of global chassis control. Vehicle System Dynamics 46(10), 889-912. 